\title{
Study On Effect of Vertical Construction Joints on Mechanical Properties of Concrete
}

\author{
Akshata C. Palkar ${ }^{1}$, Pranali M. Gawad ${ }^{2}$, Madhura S Churi ${ }^{3}$, Tanvi D. Dongare ${ }^{4}$, Ashok Meti ${ }^{5}$ \\ ${ }^{1,2,3,4}$ U.G. Student, Civil Engineering Department, St. John College of Engineering \& Management Palghar, India, 401404. \\ ${ }^{5}$ Assistant Professor, Civil Engineering Department, St. John College of Engineering \& Management Palghar, India,
}

DOI: 10.46335/IJIES.2020.5.6.9

\begin{abstract}
The purpose of this study was to experimentally correlate the difference in flexural bending capacity and splitting tensile strength, to study the general behavior of crack pattern between monolithic and non-monolithic beams and cylinder also to study the deflection of monolithic and non-monolithic beam. Mix-design was prepared using IS-10262-2019, using this mix design total twelve beams were caste in which three beams were monolithic and nine were nonmonolithic. And total twenty-four cylinders were casted in which six were monolithic and eighteen were nonmonolithic. Indian standards were used for the testing and casting of experimental specimen. For flexural strength testing ASTM C293 was used. The results shows that the monolithic cylinders have more tensile strength compare to non-monolithic cylinder. In monolithic cylinder the cracks were noticed in zigzag pattern throughout the vertical axis. In non-monolithic cylinder the cracks were developed at the vertical axial portion which was the exact center of construction joint. When the maximum failure load was reach the cylinder splits into two pieces. The beams were subjected to central concentrated loading until the failure. It was observed that for non-monolithic beam the vertical cracks were developed which was the exact location of vertical construction joint. The load deflection graph for monolithic and non-monolithic was also discussed.
\end{abstract}

Keywords- ASTM C293, Construction joint, flexural bending capacity, IS-10262-2019, monolithic, nonmonolithic, splitting tensile.

\section{I- INTRODUCTION}

$\mathbf{I}_{\mathrm{n}}$ a mass concreting works where huge volume of concrete pour is involved, it is impossible to finish the concreting in a single go, also construction joint is introduced to connect two successive pours. If completing heavy concreting is not often possible due to insufficient formwork or scaffolding, working hours in a day, limitation in production and placing machinery. In this situation, concrete is poured against as already hardened concrete face. This interface of wet and dry concrete is known as construction joint or day work joint.

Construction joint is the most commonly experienced joint in most concreting work. The intention of the joints is to allow a monolithic structure to be broken down into a series of casts of manageable size. Sometimes provisions for future extension of a building or a structure were required to be kept. In such cases construction joints were often required at the ends of the beam, slabs, tie beam etc. Construction joints were formed using bulkheads. The materials of construction joints include wood, steel, plastic or pre-cast concrete.

In this study the effect of vertical construction joint on the mechanical properties of concrete is experimentally studied. Two traditional methods were used for experimental study, the flexural strength test and splitting tensile strength test. The main purpose of 
conducting this project is to determine the difference in the bending capacity between monolithic beam and a beam with a construction joint at the beam center (i.e. non monolithic beam). Also for the difference in the split tensile strength between monolithic cylinder and cylinder with construction joint provided at the center of the cylinder (i.e. non monolithic cylinder).

\subsection{OBJECTIVES}

- To study the comparison between monolithic and vertical construction joint.

- To determine the flexural strength of monolithic and vertical construction joint of concrete.

- To determine the tensile strength of monolithic and vertical construction joint of concrete.

- To determine the deflection between monolithic and non-monolithic beams.

\subsection{AIM OF THIS STUDY}

To study the effect of vertical construction joint on the mechanical properties of concrete i.e. flexural strength and splitting tensile strength.

\section{II- METHOLOGY}

Cement, fine aggregate (crush sand), coarse aggregate $(10 \mathrm{~mm} \& 20 \mathrm{~mm})$, admixture were the material used for the concreting. The admixture used was SUNANDA (POLYCANCRETE NGT), 8mm dia. were used. The testing was done according to Indian Standard. The tested results are shown below in the table.

Table 1- Test results of cement

\begin{tabular}{|c|c|c|}
\hline $\begin{array}{c}\text { Name of the test } \\
\text { of cements }\end{array}$ & $\begin{array}{c}\text { Tested } \\
\text { results }\end{array}$ & IS code \\
\hline Fineness & $3.35 \%$ & IS-4031(Part1-1996) \\
\hline Specific gravity & 2.91 & IS-4031(Part11-1988) \\
\hline Consistency test & $32 \%$ & IS-4031(Part4-1988) \\
\hline Initial setting time & $85 \mathrm{~min}$ & IS-4031(Part5-1988) \\
\hline Final setting time & $\begin{array}{c}270 \\
\mathrm{~min}\end{array}$ & IS-4031(Part5-1988) \\
\hline
\end{tabular}

Table 2- Test results of aggregate

\begin{tabular}{|c|c|c|c|}
\hline \multirow{2}{*}{$\begin{array}{c}\text { Name of the test } \\
\text { of aggregate }\end{array}$} & \multirow{2}{*}{ F A } & \multicolumn{2}{|c|}{ Coarse aggregate } \\
\cline { 3 - 4 } & & $10 \mathrm{~mm}$ & $20 \mathrm{~mm}$ \\
\hline
\end{tabular}

\begin{tabular}{|c|c|c|c|}
\hline Fineness modulus & 2.87 & 7.07 & 7.04 \\
\hline Specific gravity & 2.61 & 2.71 & 2.76 \\
\hline Water absorption & 0.89 & 1.62 & 1.56 \\
\hline
\end{tabular}

\section{III- EXPERIMENTAL WORK}

Testing of material was done by using Indian standards. By using this test result three mix design were prepared according to IS 10262-2019. And cubes were casted for each trial. After the testing of cubes trial-1 was selected of grade M30 (1:1.39:2.56).

Twelve beams were casted in which three were monolithic and nine were non-monolithic as shown in table-3. In the nine non-monolithic beam constructions joint was provided in the Centre and at the time interval of $24 \mathrm{hrs}$, $48 \mathrm{hrs}$, and $72 \mathrm{hrs}$. The beams were tested according to ASTMC293.

Table 3-Total numbers of beam

\begin{tabular}{|c|c|}
\hline Specimen & No. of beams \\
\hline 1) Monolithic & 3 \\
\hline 2) Non-monolithic: & 3 \\
\hline a) $24 \mathrm{hrs}$ & 3 \\
\hline b) $48 \mathrm{hrs}$ & 3 \\
\hline c) $72 \mathrm{hrs}$ & 12 \\
\hline
\end{tabular}

Twenty-four cylinders were casted in which six were monolithic and eighteen were non-monolithic cylinders as shown in table-4. The joint was provided vertically at the Centre of the mould. These joints were provided at the time interval of $24 \mathrm{hrs}, 48 \mathrm{hrs}$ and $72 \mathrm{hrs}$. And the cylinders were tested according to IS 5816-1999.

Table 4- Total numbers of cylinder

\begin{tabular}{|c|c|}
\hline Specimen & No. of cylinders \\
\hline 1) Monolithic & 6 \\
\hline 2) Non-monolithic: & \\
\hline a) $24 \mathrm{hrs}$ & 6 \\
\hline b) $48 \mathrm{hrs}$ & 6 \\
\hline c) $72 \mathrm{hrs}$ & 24 \\
\hline
\end{tabular}




\section{IV-PREPARATION OF EXPERIMENT SPECIMEN}

According to IS 516-1959 and IS 5816-1999 concrete beams and cylinders were casted. For the concrete mixing, pouring, finishing and curing IS 516-1959 was used. The following steps of the work schedule were performed to prepare one full set of beams and cylinders for mix.

Total twelve beams were casted in which three beams were non-monolithic i.e. beams with vertical construction joint. A wooden plate was used to give construction joint. The wooden plate was placed perpendicular to the beam in the exact Centre of the beam mould, which was the location of the maximum bending moment and where shear force was zero. Also two bars of $8 \mathrm{~mm}$ dia. were provided in each beam as dowels bars. For non-monolithic beams this bars were inserted in the wooden plate by drilling holes providing effective cover and side cover of $30 \mathrm{~mm}$. To keep the bars at position cover blocks of slab were used.

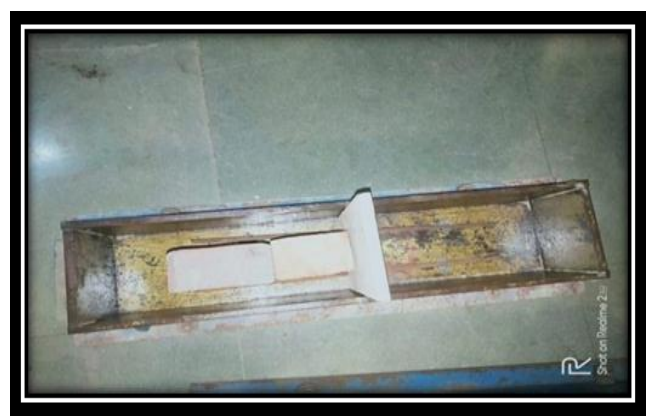

Fig. 1 - Beam with 8mm dia. bar

In addition, total twenty-four cylinders were casted for this experimental study. Out of twenty-four cylinders six cylinders were monolithic and remaining eighteen cylinders were non-monolithic i.e. contained construction joint vertically placed at the Centre of the mould. Wooden plates were used for providing construction joint and this plate was kept vertical at the Centre of the mould.

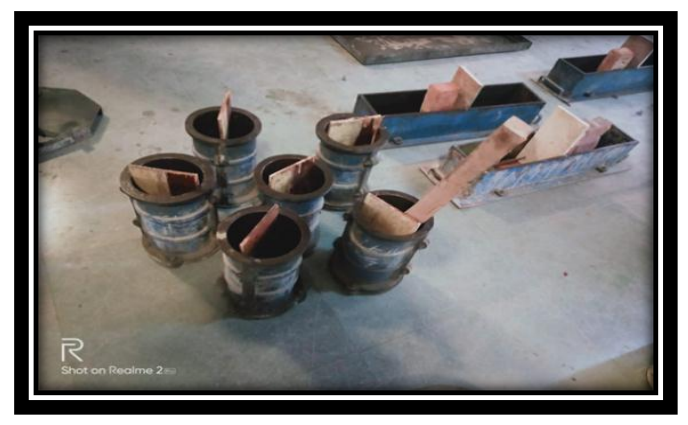

Fig. 2 -Moulds with wooden plate
The preparation of material was done according to IS 516-1959. The total concrete quantity required was calculated as per requirement by adding $10 \%$ wastage. Admixture was used in this experiment for workability purpose. The materials were filled in the buckets and weighed on the electronic balance using the scoops.

The concrete mixing was performed according to IS 516-1959. For mixing of material power driven concrete mixer or hand mixing was used depending upon quantity of material. According to IS 516-1959 and using scoops or trowels, three beams were fully filled with concrete (Monolithic beams) and the remaining three were half way-filled to the construction joint for compaction concrete table vibrator was used. Then according to IS 516-1959, six monolithic cylinders were poured with concrete and compaction was done by using concrete table vibrator.

On the first day six beams and six cylinders were casted. Here three monolithic and three half beams with construction joint were poured. In addition to that six monolithic cylinders were casted. Beam and cylinder mould were prepared according to IS 516-1959. They were cleaned and oiled in the inside face the mould. Non-monolithic beams and cylinder preliminary provided with wood wooden plates i.e. construction joint at Centre.

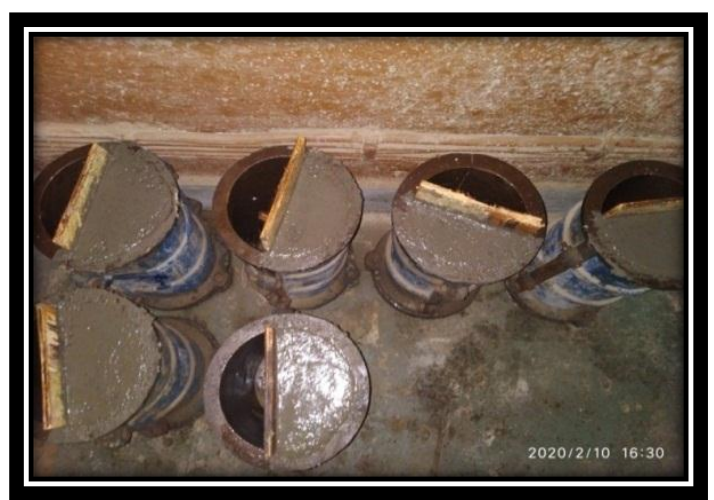

Fig. 3-Half poured cylinders

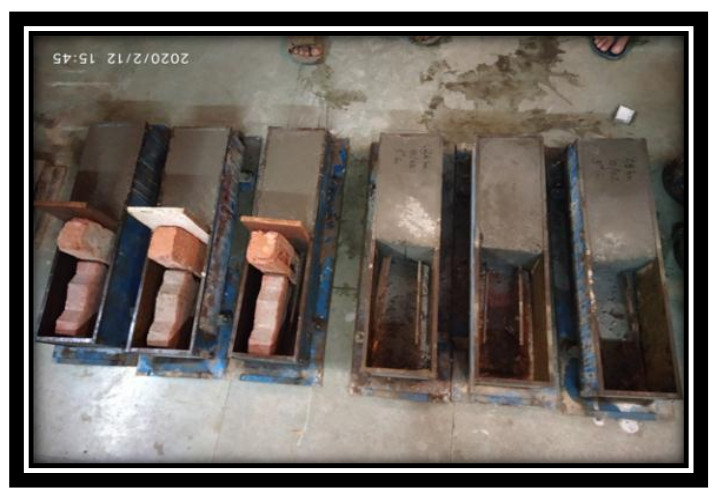

Fig. 4-Half poured beams 
On the second day, the other halves of the beams with vertical construction joint were poured for $24 \mathrm{hrs}$, nonmonolithic beams. The three monolithic beams and six monolithic cylinders were remoulded. Then this beams and cylinder stored in water tank for curing.

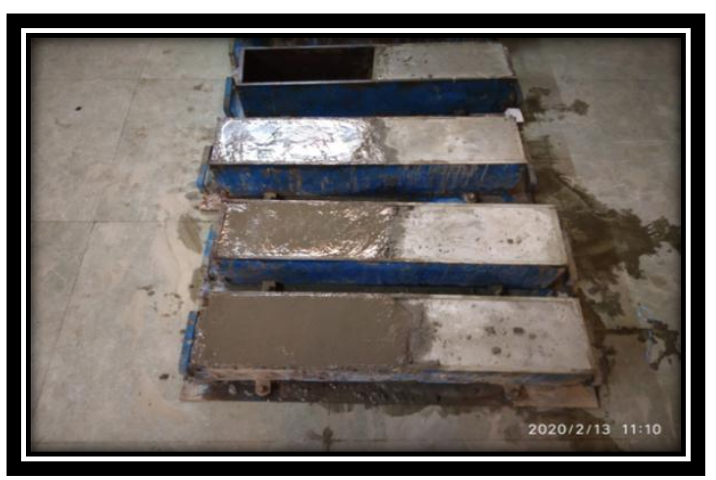

Fig. 5 -Beams with vertical construction joint

Six cylinders which were half casted and other half of the cylinders were casted after $24 \mathrm{hrs}$.

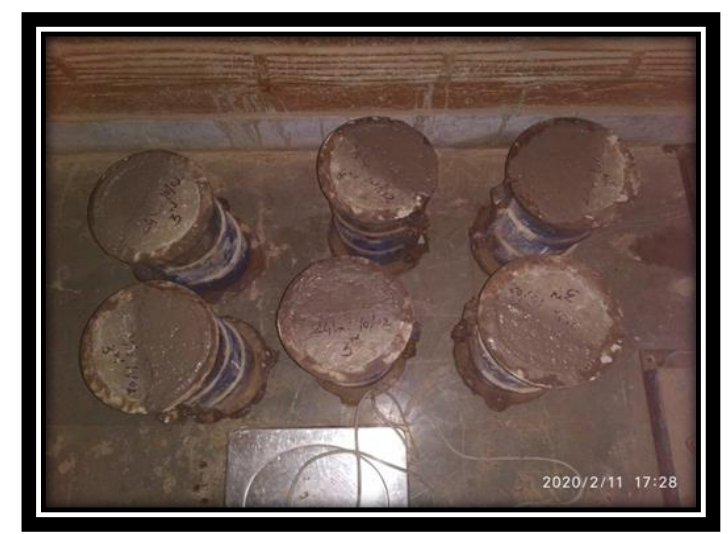

Fig. 6-Cylinders with vertical construction joint

Also for casting of 48hrs, and $72 \mathrm{hrs}$, Non-monolithic beams and cylinders procedure was followed as explained above. Also re-molding and curing was done. The hardened monolithic beams and cylinders were kept in curing tank for curing which were been taken out at the day of testing. Similarly for non-monolithic beams and cylinders the half part which was hardened was covered by wet jute bag for curing and after hardening of other half part they were in curing tank and been taken out at the kept day of testing.

\section{V-TESTING OF BEAM AND CYLINDER}

\section{Testing of beam :(ASTM C293)}

The beam samples were tested using universal testing machine (UTM) and supported simply. They were subjected to a centrally concentrated loading applied gradually until specimen failure. At each loading stage, the test measurements include the magnitude of the applied load and deflection of the beam at mid-span was recorded. At the end of each test, the cracks developed were marked and the crack pattern and mode of failure for each specimen were carefully studied.

\section{Testing of cylinder :( IS 5816-1999)}

The cylinder sample were tested using compressive testing machine (CTM) according to IS 5816-1999. As for the non-monolithic cylinders, the specimen was placed in a way that the construction joint was vertical and in the Centre and perpendicular to the plywood strip. This plywood strip was provided at the bottom and top of the cylinder. The load was applied gradually at an increment of $5 \mathrm{KN}$ until specimen failure. At each loading test, the test measurements include the magnitude of the applied load. At the end of each test, the crack patterns were carefully studied.

\section{VI- RESULTS}

\subsection{Splitting tensile strength test results}

\section{Seven days curing:}

The table-5 shows the seven days curing test results of splitting tensile strength.

Table 5- Seven days curing results for cylinder

\begin{tabular}{|c|c|c|c|}
\hline Cylinder & $\begin{array}{l}\text { Load } \\
(\mathrm{KN})\end{array}$ & $\begin{array}{l}\text { Splitting } \\
\text { tensile } \\
\text { strength }\end{array}$ & $\begin{array}{l}\text { Average } \\
\left(\mathbf{N} / \mathbf{m m}^{2}\right)\end{array}$ \\
\hline \multirow{3}{*}{$\begin{array}{l}\text { MONOLITHIC } \\
\text { (C) }\end{array}$} & 163 & 2.306 & \multirow{3}{*}{2.301} \\
\hline & 165 & 2.334 & \\
\hline & 160 & 20264 & \\
\hline \multirow{3}{*}{$\begin{array}{l}\text { NON- } \\
\text { MONOLITHIC } \\
\text { (C1) }\end{array}$} & 89 & 1.259 & \multirow{3}{*}{1.349} \\
\hline & 102 & 1.443 & \\
\hline & 95 & 1.344 & \\
\hline \multirow{3}{*}{$\begin{array}{c}\text { NON- } \\
\text { MONOLITHIC } \\
\text { (C2) }\end{array}$} & 80 & 1.132 & \multirow{3}{*}{1.146} \\
\hline & 80 & 1.132 & \\
\hline & 83 & 1.174 & \\
\hline \multirow{3}{*}{$\begin{array}{l}\text { NON- } \\
\text { MONOLITHIC } \\
\text { (C3) }\end{array}$} & 69 & 0.976 & \multirow{3}{*}{0.910} \\
\hline & 64 & 0.905 & \\
\hline & 60 & 0.849 & \\
\hline
\end{tabular}




\section{$w w w . i j i e s . n e t$}

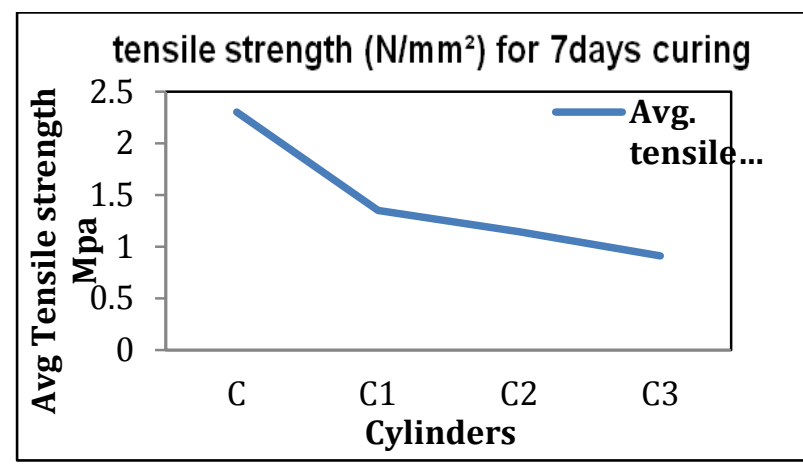

Chat 1-Average tensile strength for seven days curing

The above graph shows the splitting tensile strength variation for seven days testing. The graph was plotted against cylinders and average tensile strength of cylinders. We can see that the graph was gradually decreasing as the number of days for providing construction joint was increasing. This was due to the monolithic cylinder carries more load as compared to the non-monolithic cylinder. As the monolithic cylinder carries more loads the strength was more for monolithic cylinder carries fewer loads so the strength was also less for non-monolithic cylinder.

\section{Twenty-eight days curing:}

Table 6- Twenty-Eight days curing results for cylinder

\begin{tabular}{|c|c|c|c|}
\hline Cylinder & $\begin{array}{l}\text { Load } \\
(\mathbf{K N})\end{array}$ & $\begin{array}{l}\text { Splitting } \\
\text { tensile } \\
\text { strength }\end{array}$ & $\begin{array}{l}\text { Average } \\
\left(\mathrm{N} / \mathrm{mm}^{2}\right)\end{array}$ \\
\hline \multirow{3}{*}{$\begin{array}{l}\text { MONOLITHIC } \\
\text { (C) }\end{array}$} & 288 & 4.074 & \multirow{3}{*}{4.022} \\
\hline & 280 & 3.961 & \\
\hline & 285 & 4.032 & \\
\hline \multirow{3}{*}{$\begin{array}{l}\text { NON- } \\
\text { MONOLITHIC } \\
\text { (C1) }\end{array}$} & 251 & 3.551 & \multirow{3}{*}{3.410} \\
\hline & 242 & 3.424 & \\
\hline & 230 & 3.254 & \\
\hline \multirow{3}{*}{$\begin{array}{l}\text { NON- } \\
\text { MONOLITHIC } \\
(\mathrm{C} 2)\end{array}$} & 208 & 2.943 & \multirow{3}{*}{2.905} \\
\hline & 198 & 2.801 & \\
\hline & 210 & 2.971 & \\
\hline \multirow{3}{*}{$\begin{array}{l}\text { NON- } \\
\text { MONOLITHIC } \\
\text { (C3) }\end{array}$} & 94 & 1.330 & \multirow{3}{*}{1.410} \\
\hline & 106 & 1.500 & \\
\hline & 99 & 1.401 & \\
\hline
\end{tabular}

Table-6 shows that the experimental test results for splitting tensile strength for 28 days curing. The avg. tensile strength was calculated for cylinders C, C1, C2 and $\mathrm{C} 3$.

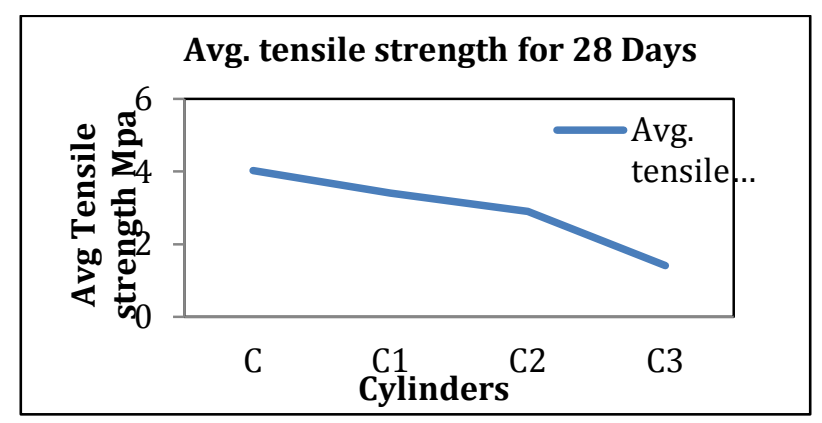

Chat 2-Average tensile strength for twenty-eight days curing

The above graph shows variation of splitting tensile strength for monolithic and non-monolithic cylinder. Here, also the graph was plotted against average tensile strength and cylinder. We can see that the graph was gradually decreasing as the time consumption was more for casting of non-monolithic cylinder. For nonmonolithic cylinders, the cylinders which were casted after $24 \mathrm{hrs}$ carry more loads having more splitting tensile strength as compared to cylinders casted after $48 \mathrm{hrs}$ and $72 \mathrm{hrs}$. Also for $48 \mathrm{hrs}$ cylinder carry more loads as compared to the cylinder casted after $72 \mathrm{hrs}$. But we can see that monolithic cylinder carries more load and tensile strength as compared to the all the nonmonolithic cylinder.

\subsection{General behavior of crack pattern for cylinder Monolithic cylinder:}

Splitting tensile strength was performed on monolithic cylinder to evaluate the strength performance \& cracking behavior under different end conditions. It has been observed that the vertical axial crack was developed in the monolithic cylinder. The cracks were noticed in zigzag pattern throughout the vertical axis.

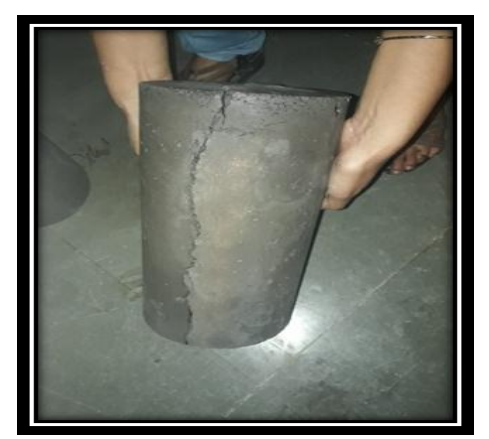

Fig. 7 - Crack in monolithic cylinder 


\section{Non-monolithic cylinder:}

As we were giving the construction joint at the middle of cylinders at the time interval of $24 \mathrm{hr}, 48 \mathrm{hr}, 72 \mathrm{hr}$ respectively. When the non-monolithic cylinders were tested, the load was increased gradually and it has been observed that, the cracks were developed at the vertical axial portion which was the exact center of construction joint. When the maximum failure load was reach the cylinder splits into two pieces as shown in fig.

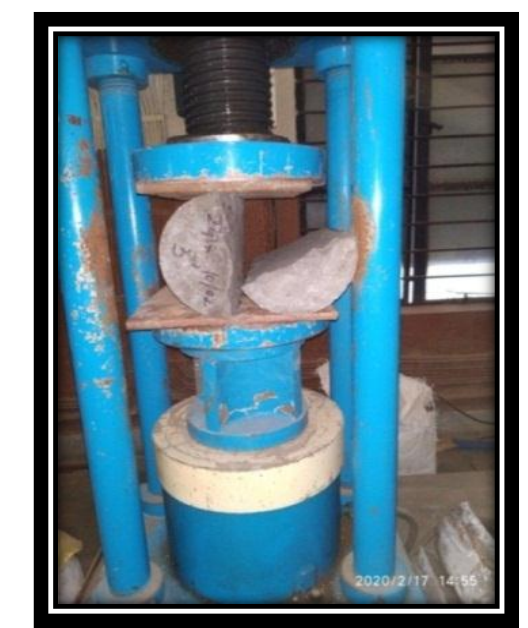

Fig. 8-Crack in non-monolithic cylinder

\subsection{Flexural strength test results}

\section{Twenty-eight days curing:}

The flexural strength for monolithic and non-monolithic beam i.e. B, B1, B2 and B3 was calculated in the Table6 and shown below.

Table 7- Twenty-Eight days curing results for beam

\begin{tabular}{|c|c|c|c|}
\hline Beams & $\begin{array}{l}\text { Load } \\
(\mathrm{KN})\end{array}$ & $\begin{array}{l}\text { Flexural } \\
\text { Strength } \\
\left(\mathbf{N} / \mathbf{m m}^{2}\right)\end{array}$ & $\begin{array}{l}\text { Average } \\
\left(\mathrm{N} / \mathrm{mm}^{2}\right)\end{array}$ \\
\hline \multirow{3}{*}{$\begin{array}{c}\text { MONOLITHIC } \\
\text { (B) }\end{array}$} & 81.88 & 25.474 & \multirow{3}{*}{24.130} \\
\hline & 76.60 & 23.831 & \\
\hline & 74.20 & 23.084 & \\
\hline \multirow{3}{*}{$\begin{array}{c}\text { NON- } \\
\text { MONOLITHIC } \\
\text { (B1) }\end{array}$} & 68.80 & 21.404 & \multirow{3}{*}{20.025} \\
\hline & 57.40 & 170858 & \\
\hline & 56.90 & 20.813 & \\
\hline \multirow{2}{*}{$\begin{array}{c}\text { NON- } \\
\text { MONOLITHIC }\end{array}$} & 65.30 & 20.316 & \multirow{2}{*}{20.191} \\
\hline & 68.10 & 21.187 & \\
\hline
\end{tabular}

\begin{tabular}{|c|c|c|c|}
\hline (B2) & 61.30 & 19.074 & \\
\hline \multirow{2}{*}{$\begin{array}{c}\text { NON- } \\
\text { MONOLITHIC } \\
(B 3)\end{array}$} & 67.90 & 21.124 & \multirow{2}{*}{19.786} \\
\cline { 2 - 3 } & 63.70 & 19.818 & \\
\cline { 2 - 3 } & 59.20 & 18.418 & \\
\hline
\end{tabular}

The flexural test for monolithic and non-monolithic beam has been carried out to make comparison of bending capacity between monolithic and nonmonolithic beams.

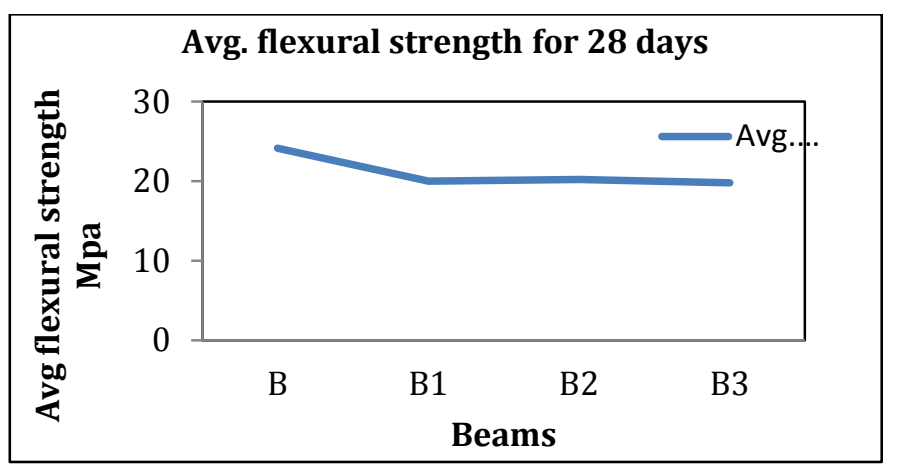

Chat 3-Average Flexural strength for twenty-eight days curing

The above graph shows the variation in average flexural strength. Average flexural strength for monolithic beam was $24.130 \mathrm{~N} / \mathrm{mm}^{2}$. But if we compare the beam B1, B2 and B3 were not more difference in their average flexural strength. Hence graph shows somewhat straight line. From the graph we can say that the average flexural strength of non-monolithic beam was $85 \%$ of monolithic beams. It means that if we were casting structure with construction joint after some time interval then there was not much loss of flexural strength in the structure.

\subsection{General Behavior of Crack Pattern for Beam}

\section{Monolithic beam}

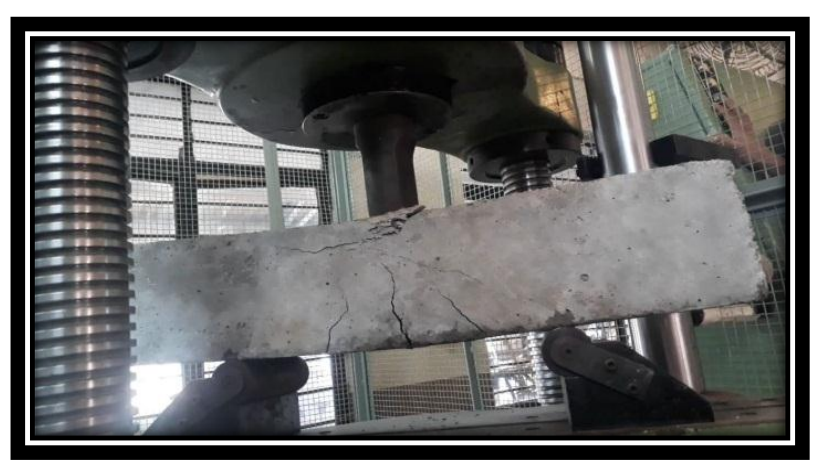

Fig. 9 - Crack in monolithic beam 
The fig-9 shows the behavior of crack pattern in monolithic beam. In the monolithic specimen the crack propagations occurs slowly until the peak load and collapse occurs. The first crack develops at the beam center at stress which was close to the flexural strength of concrete. Crack prorogation that occurs on the beam continues to grow and extend along with increasing load.

As the load increases, several other cracks on both sides of the central region developed. Crack prorogation on the beam stops when maximum failure load was reach.

Failure occurs at the $81.88 \mathrm{KN}, 76.60 \mathrm{KN}$ and $74.20 \mathrm{KN}$ for monolithic beams and the measured deflection were $3.2 \mathrm{~mm}, 2.0 \mathrm{~mm}$ and $2.3 \mathrm{~mm}$ respectively.

\section{$\underline{\text { Non-monolithic beam }}$}

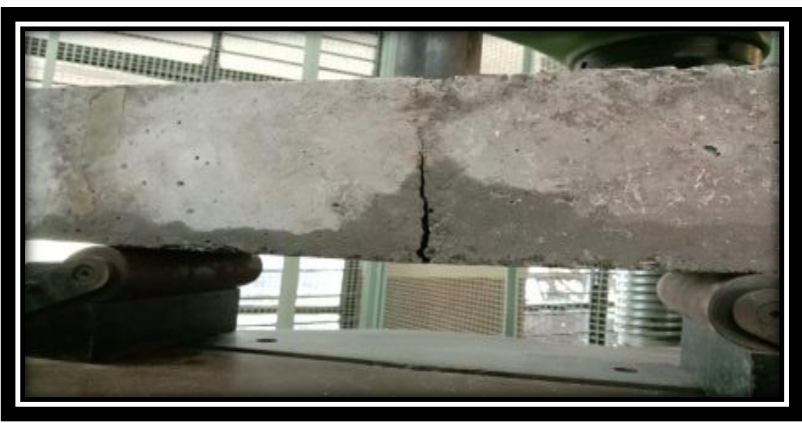

Fig. 10 - Crack in non-monolithic beam

Crack pattern and damage to the non-monolithic specimens can be seen in fig-10. The beam was placed in UTM (universal testing machine) for flexural strength testing as the load applied for all the specimens, the first crack was initiated from the bottom of the beam in the mid-span where the maximum bending moment occurred.

In non-monolithic beam, the crack prorogation occurs very quickly until peak load and collapse occur. Crack prorogation that occurs on the beam extends along with the increases load. As the applied load increased it was observed that, the first crack widened and propagated vertically upward. It was observed that, the collapse occurs when the crack in the beam reaches half the height of the beam. In general, all the specimens, B, B1, B2 and B3 were failed in a ductile mode by excessive yielding of tension steel reinforcement and a concert crushing at the top surface.

\subsection{Load Deflection Graphs for beam}

The load deflection curves for beams having construction joint (i.e. non-monolithic beam) were compared with load deflection curves for beams without construction joint (i.e. monolithic beam) as shown in graph below. The graph was plotted against load (KN) and deflection $(\mathrm{mm})$.Vertical deflection at the mid-span was recorded at each load step of the test program and according to these readings graphs were plotted.

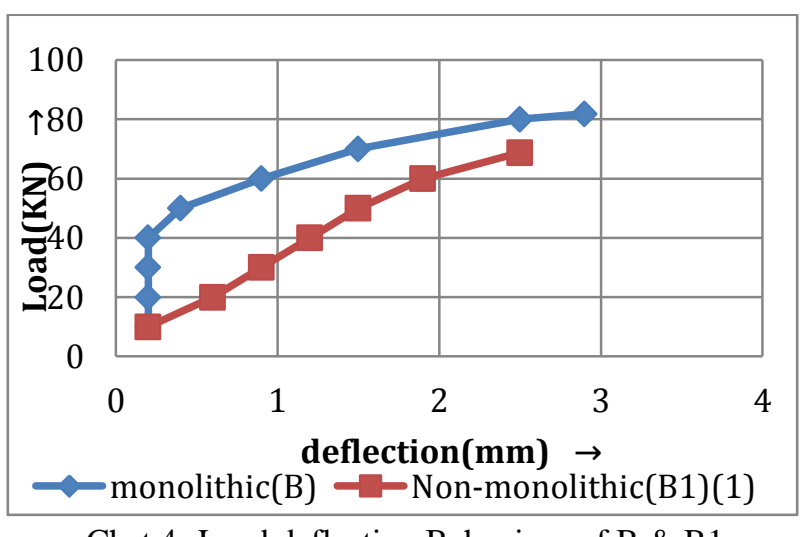

Chat 4- Load deflection Behaviour of B \& B1

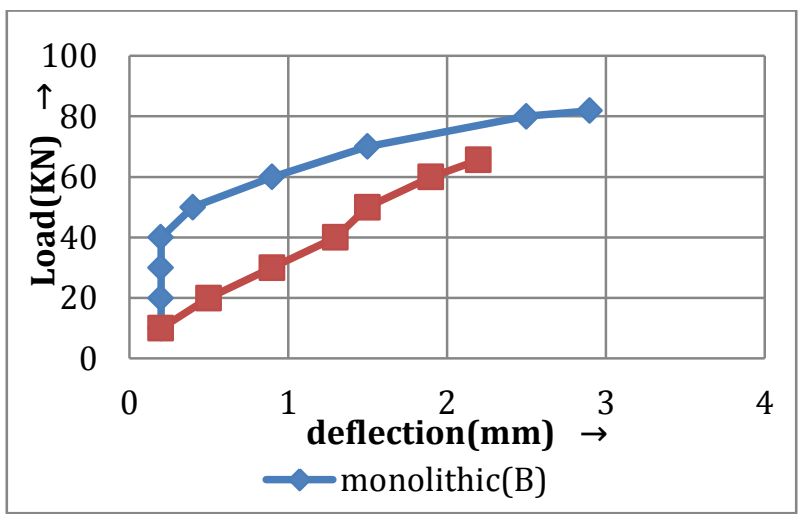

Chat 5- Load deflection Behaviour of B \& B2

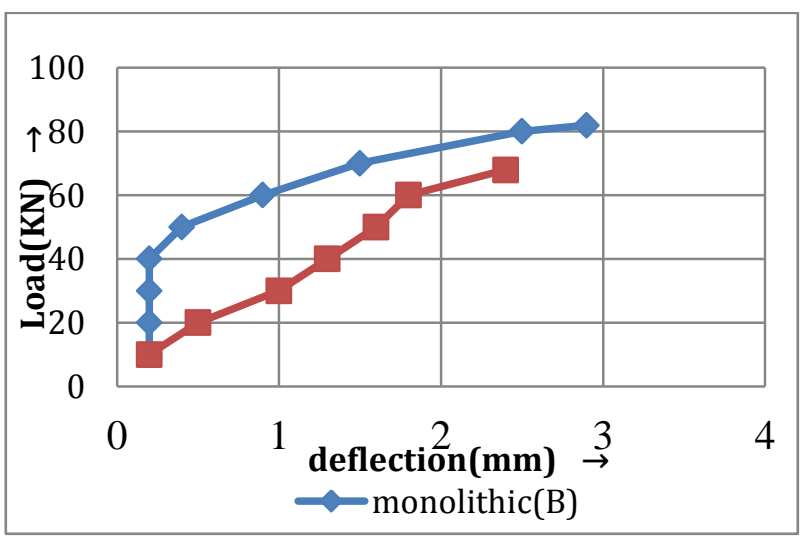

Chat 6- Load deflection Behaviour of B \& B3

Generally when the monolithic beam was progressively loaded, the deflection was constant till the $40 \mathrm{KN}$ and the deflection was $0.2 \mathrm{~mm}$. Thereafter the cracks were developed; the deflection was increases as shown in all the graphs. After developing of crack in the monolithic 
beam, the load deflection responses remain somewhat linear.

For non-monolithic beams graphs were plotted for B1, B2 and B3 and these curves were compared with monolithic beam. When the beam was loaded the cracks were developed at the center of the beam which was the exact location of the construction joint. Load-deflection curve increases linearly from the starting of application of load. And the curves remain linearly till the beam reaches its failure load. The all the non-monolithic beam (i.e. B1, B2 and B3) have same behavior as explain above. There was no rapid change in deflection of nonmonolithic beams.

\section{VII- CONCLUSIONS}

- In this study it was found that as the days goes on increasing for concreting the tensile strength decreases for cylinders containing vertical construction joint also tensile strength of nonmonolithic cylinder was less when compared to monolithic cylinder.

- For monolithic cylinder, it has been observed that the vertical axial crack was developed. The cracks were noticed in zigzag pattern throughout the vertical axis and for nonmonolithic cylinder the cracks were developed at the vertical axial portion which was the exact center of construction joint. When the maximum failure load was reach the cylinder splits into two pieces.

- The load carrying capacity for the tested beams with vertical construction joint was about $85 \%$ of the capacity of the monolithic beam i.e. beams without construction joint. Vertical construction joints have a slight effect on the overall behavior of reinforced concrete beams under flexural mode when they were placed at the middle of the beam span.

- For the non-monolithic beams as the load increases, the first crack was initiated at the mid-span and at the failure stage the first crack was widened and propagated vertically upward, when monolithic beam was progressively loaded the deflection was increasing at an elastic juncture. At first central crack were appeared and several other flexural cracks on the both side of the central region developed.

- For the non-monolithic beam the loaddeflection curve was increasing linearly but for monolithic beam as the load increases the deflection remains constant, after the developing of crack the load-deflection response was increasing linearly.

\section{REFERENCES}

[1] Camille A Issa, Nagib N Gerges, Sameer Fawaz, The effect of concrete vertical construction joints on modules of rupture, case studies in construction materials (2014)25-32 (www. Elsevier.com)

[2] Nagib N Gerges, Camille A. Issa, Samer Fawaz, Effect of construction joints on splitting tensile strength of concrete, case studies in construction materials 3(2015) 83-91.science direct.com

[3] Nagib N Gerges, Camille A Issa, Samer Fawaz, The effect of construction joint on flexural bending capacity of singly reinforced beams, case studies in construction materials 5 (2016) 112-123.

[4] IS 10262 - 2019, concrete mix proportioningGuidelines (second revision) Doc no.CED (11290).

[5] Book by M.S shetty, Concrete Technology: Theory and practice originally published: 1982.

[6] IS 1489 (part 1) 1991 specification for Portland pozzolana cement, Fly ash based (third revision), first reprint march 1993, Bureau of Indian Standards.

[7] IS 383-1970 specification for coarse \& fine aggregate, Reaffirmed 2007, Bureau of Indian Standards.

[8] IS 2386 (part1) 1963 Methods of tests for aggregate for concrete particle size and shape (eleventh reprint August 1997) reaffirmed 2002, Bureau of Indian Standards.

[9] IS 2386 (part 3) 1963 Methods of test for aggregate for specific gravity, density, voids, absorption, (eight reprint march 1997) reaffirm 2002, Bureau of Indian Standards .

[10] IS 2386 (part 5) 1963 methods of test for aggregate soundness, reaffirmed 2002, Indian Standard Institution.

[11] IS 2386 (part 4) 1963 Methods of test for aggregate for mechanical properties, tenth reprint, March 1997, reaffirmed 2002, Bureau of Indian Standards

[12] IS 516 - 1959 Methods of tests for strength of concrete (eighteenth revision) Reaffirmed - May 2019.

[13] 7. IS 5816-1999, Methods of splitting tensile strength of concrete, Bureau of Indian standards (BIS) ,CED 2.

[14] Hussain Aakar Jabir, Effect of construction joints on behavior of reinforced concrete beams, www.researchgate.net, article May -2017.

[15] Lopez Batiz, Behaviour of reinforced concrete frame structures with construction joints under lateral loads, publication : ICE, magazine of concrete research, vol. 50 issue 2, june 1998

[16] Mohammad Hari Bin Osmsn, A comparison of construction joint ability of concrete slab applied at construction site, publication : ARPN journal of engineering and applied sciences, vol. 11 no. 4. 
International Journal of Innovations in Engineering and Science, Vol 5, No.6, 2020

\section{$w w w . i j i e s . n e t$}

[17] ASTM C293 / C293M - 16 Standard test method for flexural strength of concrete (using simple beam with center-point loading) standard by ASTM international, 04/15/2016

[18] Hussain Aakar Jabir, Thaar Sauid Salman, Jasim Mahalha, Effect of construction joints on the behavior of reinforced beams, by journal of engineering, vol no5, 23 May 2013.

[19] Kirillov A.P, Effect of construction joints on performance of reinforced concrete structures, Hydro technical construction 3, 214-22 (1969), march 1969.

[20] S. Ishihara, H.Mihashi, Experimental study on mechanical behavior in construction joints of concrete structures, Fracture mechanics of concrete structures, proceedings FRAMCOS-3 